\title{
IN VITRO: NATURAL COMPOUNDS (THYMOL, CARVACROL, HESPERIDINE, AND THYMOQUINONE) AGAINST SARS-COV2 STRAIN ISOLATED FROM EGYPTIAN PATIENTS
}

\author{
Seadawy M.G ${ }^{1 *}$, Gad, A.F ${ }^{1}$, Elhoseny, M.F ${ }^{1}$, ELharty, B.El ${ }^{1}$, Shamel, M.D ${ }^{1}$,Abdo A. Elfiky ${ }^{2}$, \\ Aya Ahmed ${ }^{3}$, Abdel Rahman N. Zekri ${ }^{4}$ \\ 1* Main chemical laboratories, Egypt Army \\ ${ }^{2}$ Biophysics Department, Faculty of Science, Cairo University \\ ${ }^{3}$ Molecular Virology and Immunology Unit, Cancer Biology Department, National Cancer \\ Institute, Cairo University, Cairo, Egypt. \\ ${ }^{4}$ National Cancer Institute, Cairo University, Giza, Egypt
}

*corresponding author: Seadawy M.G ${ }^{1}$ Main chemical laboratories, Egyptian Army, Egypt. Mobile: +201000948658

E-mail: biologist202054@yahoo.com

\begin{abstract}
The current pandemic of the coronavirus disease-2019 (COVID-19) has badly affected our life during the year 2020. SARS-CoV-2 is the primary causative agent of the newly emerged pandemic. Natural flavonoids, Terpenoid and Thymoquinone are tested against different viral and host-cell protein targets. These natural compounds have a good history in treating Hepatitis $\mathrm{C}$ Virus (HCV) and Human Immunodeficiency Virus (HIV). Molecular docking combined with cytotoxicity and plaque reduction assay is used to test the natural compounds against different viral (Spike, RdRp, and $\mathrm{M}^{\mathrm{pro}}$ ) and host-cell (TMPRSS II, keap 1, and ACE2) targets. The results demonstrate the binding possibility of the natural compounds (Thymol, Carvacrol, Hesperidine, and Thymoquinone) to the viral main protease $\left(\mathrm{M}^{\mathrm{pro}}\right)$. Some of these natural compounds were approved to start clinical trail from Egypt Center for Research and Regenerative Medicine ECRRM IRB (Certificate No.IRB00012517)
\end{abstract}

\section{Keywords:}

COVID-19; SARS-CoV-2; Natural products; antivirals; docking; plaque reduction assay. 


\section{Introduction}

By the end of 2019, an outbreak of a novel coronavirus (SARS-CoV-2) in Wuhan city in China was detected and spread all over the world ${ }^{1}$. On $10^{\text {th }}$ October 2020, the number of confirmed cases of coronavirus disease (COVID-19) reached more than $37 \mathrm{M}$ worldwide with $+1 \mathrm{M}$ total death, as reported in the World Health Organization (WHO). The associated pneumonia with the novel viral infection, COVID-19, is divided into three phases that correspond to different clinical stages of the disease ${ }^{2}$. Stage 1 is the asymptomatic stage, where the inhaled virus binds to nasal epithelial cells in the nasal cavity and starts replicating. Stage 2 is the upper airway stage, where the virus propagates, migrates down the respiratory tract along the conducting airways, and a more robust innate immune response is triggered. About $20 \%$ of the infected patients will progress to stage 3 disease and develop pulmonary infiltrates. Some of these patients will develop a very severe disease as the virus reaches alveoli in the lung and infects alveolar type II cells in peripheral and sub-pleural areas of the lung ${ }^{3}$. SARS-CoV-2 propagates within type II cells, large numbers of viral particles are released, and the cells undergo apoptosis and die. Therefore, the spectrum of symptomatic COVID-19 ranges from mild respiratory tract infection to severe pneumonia that may progress to fatal respiratory syndrome and multi-organ malfunctions ${ }^{2}$.

Thymol, known as 2-isopropyl-5-methylphenol, is a natural monoterpenoid phenol derivative of Cymene. It is found in thyme oil and extracted from Thymus vulgaris ${ }^{4}$. Thymol is a white crystalline substance that has a pleasant aromatic odor. Thymol also provides the distinctive and robust flavor of the culinary herb thyme.

Carvacrol is known as monoterpenoid phenol and extracted from Oregano. It has a characteristic pungent and warm odor ${ }^{5}$. 
Hesperidine is a common flavone glycoside found in citrus fruit such as lemons and sweet oranges ${ }^{6,7}$. It has several pharmacological activities such as antihyperlipidemic, antiatherogenic, venotonic, antidiabetic, cardioprotective, anti- antihypertensive, and inflammatory actions ${ }^{6,7}$. The anti-inflammatory activity of hesperidin was mainly attributed to its antioxidant defense mechanism and suppression of pro-inflammatory cytokine production ${ }^{6}$. Hesperidin exhibited antiviral activity against the influenza virus through a significant reduction of viral replication.

Nigella sativa (NS) contains many active molecules, such as thymoquinone (TQ), two forms of alkaloids: isoquinoline alkaloid that includes nigellicimine, nigellicimine n-oxide and pyrazol alkaloid that includes nigellidine and nigellicine ${ }^{8,9}$. TQ is the most abundant constituent in the volatile oil of Nigella sativa seeds, and most of the herb's properties are attributed to it ${ }^{10,11}$. It has been reported that NS oil can decrease the viral count of HCV in patients received capsules of NS oil $(450 \mathrm{mg})$ three times a day over a 3 -month period ${ }^{12}$. Moreover, two clinical studies documented to sustained sero-reversion of the HIV virus over treatment period of 6 to 12 months ${ }^{13-15}$.

Molecular docking represents a promising in silico method used to predict the binding affinities of small molecules to proteins as a first step in structure based drug design ${ }^{16-21}$. This study investigated many active ingredients that showed antiviral activities against SARS-CoV-2, such as Thymol, Carvacrol, Hesperidine, and Thymoquinone. Molecular docking is used to test the binding affinities of these natural product derived compounds against different viral and host cell proteins. Additionally cytotoxicity assay and plaque reduction assay are used to verify their antiviral activity against SARS-CoV-2 collected from Egyptian patients. 


\title{
Materials and methods
}

\author{
In silico testing:
}

Before performing the docking studies, the tested compounds are retrieved from the PubChem database and then prepared using PyMOL software ${ }^{22,23}$. The structures of the proteins are downloaded from the protein data bank ${ }^{24}$. Autodock Tools are used to prepare the docking input files after adding charges ${ }^{25}$. The docking experiments are performed utilizing Autodock Vina software in triplicates to have a clear depiction of the mode of action of compounds against their protein targets ${ }^{26}$. SARS-CoV-2 Spike protein (S), The RNA dependent RNA polymerase $(\mathrm{RdRp})$, the main protease $\left(\mathrm{M}^{\mathrm{pro}}\right)$ are used as protein targets due to its critical role in maintaining the viral infection ${ }^{27-31}$. Additionally, the host-cell receptors, Transmembrane protease, serine 2 (TMPRSS II), Kelch-like ECH-associated protein 1 (KEAP 1) and the Angiotensin Converting Enzyme 2 (ACE2) are targeted due to its fundamental in viral recognition and maintain infectivity for SARS-CoV-2 ${ }^{32-35}$. For each compound, ten interactions were generated and one with best binding affinity was selected. PyMOL software was used to represent and analyze the docking complexes.

\section{Experimental section:}

All the chemical compounds are purchased from different sources as follow; Thymol purchased from upnature as THYME $100 \%$ pure and natural $118 \mathrm{ml}$, Carvacrol purchased from Zane Hellas as oil of Oregano $30 \mathrm{ml}$, Hesperidin purchased from science-based nutrition as hesperidin methyl chalcone $500 \mathrm{mg}$-60 veggie caps, and Thymoquinone purchased from prime natural black seed USDA organic $240 \mathrm{ml}$. 


\section{A) Cytotoxicity assay}

Samples were diluted with Dulbecco's Modified Eagle's Medium (DMEM). Stock solutions of the test compounds were prepared in $10 \%$ DMSO in $\mathrm{ddH}_{2} \mathrm{O}$. The cytotoxic activity of the extracts were tested in Vero E6 cells by using the 3-(4, 5-dimethylthiazol -2yl)-2, 5-diphenyltetrazolium bromide (MTT) method ${ }^{36}$ with minor modification. Briefly, the cells were seeded in 96 well-plates $\left(100 \mu \mathrm{l} /\right.$ well at a density of $3 \times 10^{5}$ cells/ml $)$ and incubated for $24 \mathrm{hrs}$ at $37^{\circ} \mathrm{C}$ in $5 \% \mathrm{CO}_{2}$. After $24 \mathrm{hrs}$, cells were treated with various concentrations of the tested compounds in triplicates. After further $24 \mathrm{hrs}$, the supernatant was discarded and cell monolayers were washed with sterile phosphate buffer saline (PBS) 3 times and MTT solution (20 $\mu \mathrm{l}$ of $5 \mathrm{mg} / \mathrm{ml}$ stock solution) was added to each well and incubated at $37^{\circ} \mathrm{C}$ for 4 hrs followed by medium aspiration. In each well, the formed formazan crystals were dissolved with $200 \mu \mathrm{l}$ of acidified isopropanol $(0.04 \mathrm{M} \mathrm{HCl}$ in absolute isopropanol $=0.073 \mathrm{ml} \mathrm{HCL}$ in $50 \mathrm{ml}$ isopropanol). Absorbance of formazan solutions were measured at $\lambda_{\max } 540 \mathrm{~nm}$ with $620 \mathrm{~nm}$ as a reference wavelength using a multi-well plate reader. The percentage of cytotoxicity compared to the untreated cells was determined with the following equation.

$\%$ cytotoxity $=\frac{\text { (absorbance of colls without treatmant - absorbance of colls with treatment) X100 }}{\text { absorbance of colls without treatment }}$

The plot of \% cytotoxicity versus sample concentration was used to calculate the concentration which exhibited $50 \%$ cytotoxicity (IC50).

\section{B) Plaque reduction assay}

Assay was carried out according to the method of ${ }^{37}$ in a six well plate where Vero E6 cells $\left(10^{5}\right.$ cells $\left./ \mathrm{ml}\right)$ were cultivated for $24 \mathrm{hrs}$ at $37^{\circ} \mathrm{C}$. Sever Acute Respiratory Syndrome 
Coronavirus (SARS-CoV2) virus was diluted to give $103 \mathrm{PFU} /$ well and mixed with the safe concentration of the tested compounds and incubated for 1 hour at $37^{\circ} \mathrm{C}$ before being added to the cells. Growth medium was removed from the cell culture plates and the cells were inoculated with $(100 \mu \mathrm{l} /$ well) virus with the tested compounds, After 1 hour contact time for virus adsorption, $3 \mathrm{ml}$ of DMEM supplemented with $2 \%$ agarose and the tested compounds was added onto the cell monolayer, plates were left to solidify and incubated at $37^{\circ} \mathrm{C}$ till formation of viral plaques (3 to 4 days). Formalin (10\%) was added for two hours then plates were stained with $0.1 \%$ crystal violet in distilled water. Control wells were included where untreated virus was incubated with Vero E6 cells and finally plaques were counted and percentage reduction in plaques formation in comparison to control wells was recorded as following:

$\%$ inhibition $=[$ viral count $($ untreated $)-$ viral count $($ treated $) /$ viral count $($ untreated $)] \times 100$.

-Statistical analysis:

Analysis was performed using Graphpad Prism 8.0.2. Data are represented as mean \pm SD and statistical significance was evaluated using one-way ANOVA followed by tukey multiple comparison tests.

\section{Results and discussion}

Many reports showed that different natural product derived compounds have promising results against inflammation and viral infections including the newly emerged viral infection (SARS-CoV-2) ${ }^{15,38-40}$. Different natural compounds and their derivatives proved its binding affinity against different SARS-CoV-2 and host-cell targets ${ }^{38,39,41}$.

Figure 1 shows the 2D structures of the selected natural compounds used in the current study against viral and host-cell protein targets. 


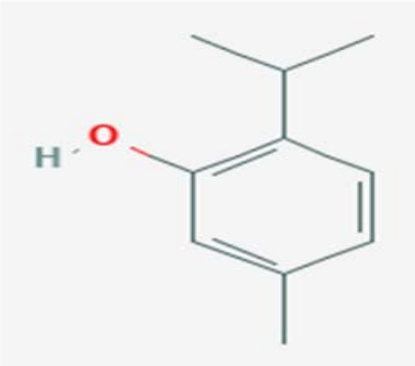

Thymol

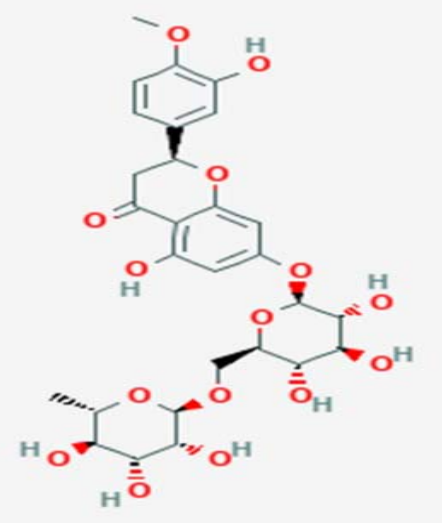

Hesperidin

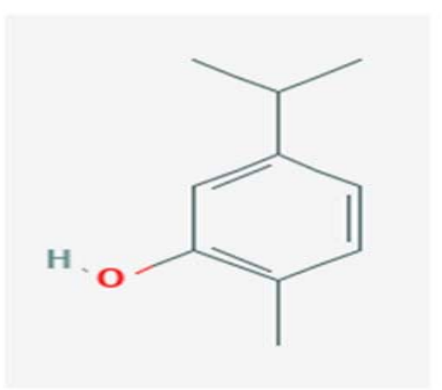

Carvacrol

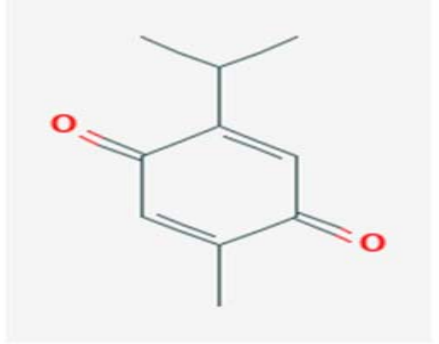

Thymoquinone

Figure 1 The structures of the natural compounds used in the study retrieved from the PubChem database.

Three SARS-CoV-2 proteins are targeted in this study including the viral, host-cell recognizing critical element, spike protein (Figure 2A), the vital viral enzyme RNA dependent RNA polymerase (RdRp), responsible for the polymerization of the complement RNA copy, and the Main protease $\left(\mathrm{M}^{\mathrm{pro}}\right)$ of SARS-CoV-2, which is critical for polyprotein processing (Figure 2B) ${ }^{42-47}$. The spike protein trimers over the virions take different conformations during infection such as the prefusion and postfusion. The prefusion has open and closed conformations in which one or two of the receptor binding domains (RBD) are exposed (open) or immersed into the trimer (close) ${ }^{30,48}$. 

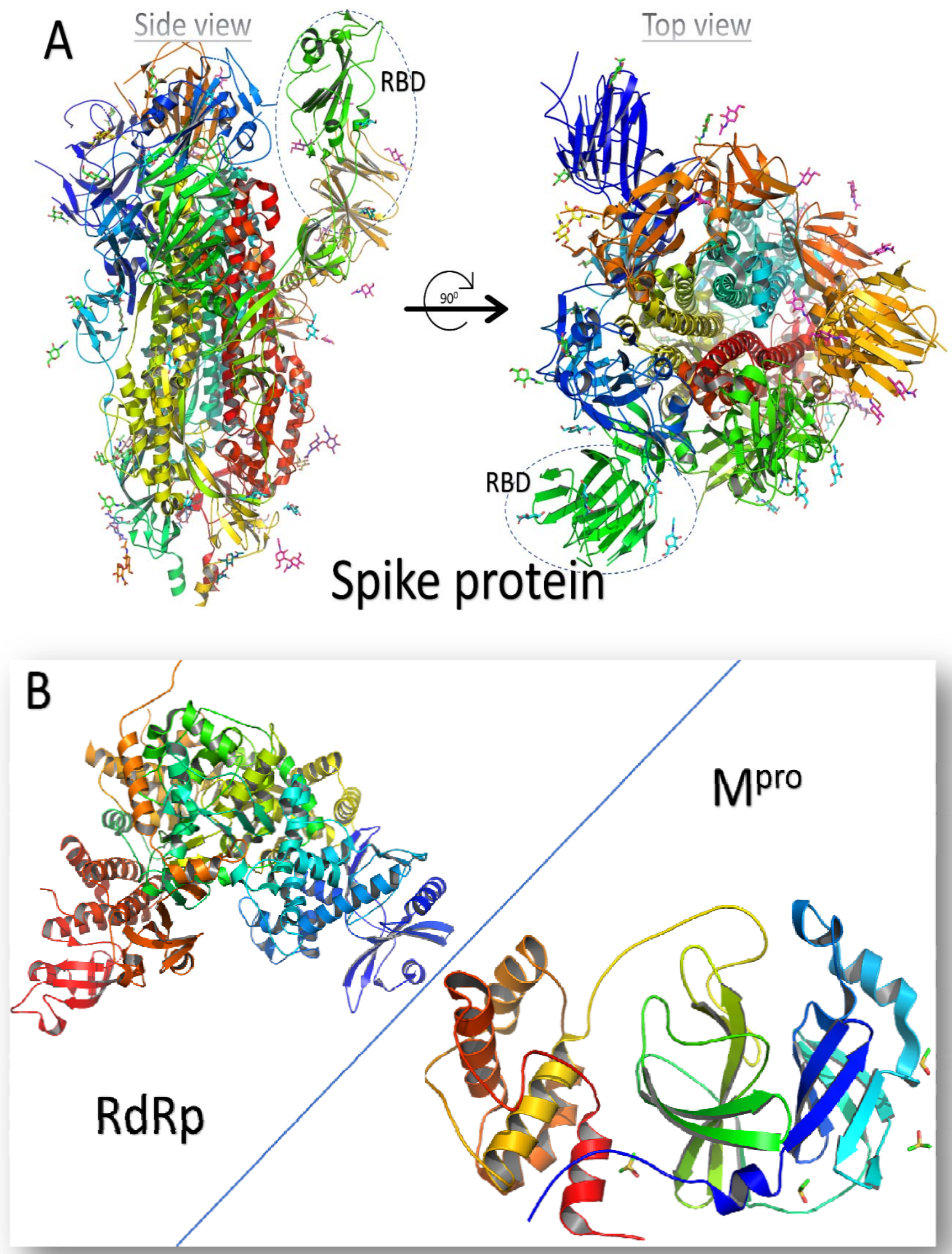

Figure 2 The 3D structures of the SARS-CoV-2 protein targets used in the study. A) The structure of SARS-CoV-2 Spike protein (PDB ID: 6VYB) represented by colored cartoons in side (left) and top (right) views. The receptor binding domain (RBD) is encircled in both views of the spike. B) The structure of the SARS-CoV-2 RdRp (PDB ID: $7 B T F)$ and $M^{\text {pro }}$ (PDB ID: 6Y84) depicted in colored cartoons. The structures are represented using PYMOL software. 
Table 1 shows the binding affinity calculated using AutoDock Vina software for the docking of the natural compounds (Thymol, Carvacrol, Hesperidine, and Thymoquinone) against the SARS-CoV-2 $\mathrm{M}^{\text {pro }}$ as a protein target. The standard compound Chloroquine is used to assess the binding affinity of the natural compounds against the $\mathrm{M}^{\text {pro }}$. As reflected from the values, Carvacrol, Hesperidine, and Thymoquinone show comparable binding affinities (-7.0, -6.9, and $6.9 \mathrm{kcal} / \mathrm{mol}$, respectively) to SARS-CoV-2 $\mathrm{M}^{\text {pro }}$ compared to that of the standard compound ($7.2 \mathrm{kcal} / \mathrm{mol})$. Thymol show slightly higher (worse) binding affinity value $(-5.8 \mathrm{kcal} / \mathrm{mol})$ compared to Chloroquine but still able to bind the SARS-CoV-2 $\mathrm{M}^{\text {pro }}$ tightly. Figures $3 \mathrm{~A}$ and 3B show the 3D poses for the docking complexes. The four compounds (Thymol, Carvacrol, Hesperidine, and Thymoquinone) are able to bind to the active site of the $\mathbf{M}^{\text {pro }}$ (His41 and Cys145).

Table 1 The binding affinity (in $\mathrm{kcal} / \mathrm{mol}$ ) of the natural compounds against the main protease of SARS-CoV-2 calculated using AutoDock Vina software.

\begin{tabular}{|c|c|}
\hline Compound & Binding affinity $(\mathrm{kcal} / \mathrm{mol})$ \\
\hline Thymol & -5.8 \\
\hline Carvacrol & -7.0 \\
\hline Hesperidine & -6.9 \\
\hline Thymoquinone & -6.9 \\
\hline Chloroquine(standard) & -7.2 \\
\hline
\end{tabular}



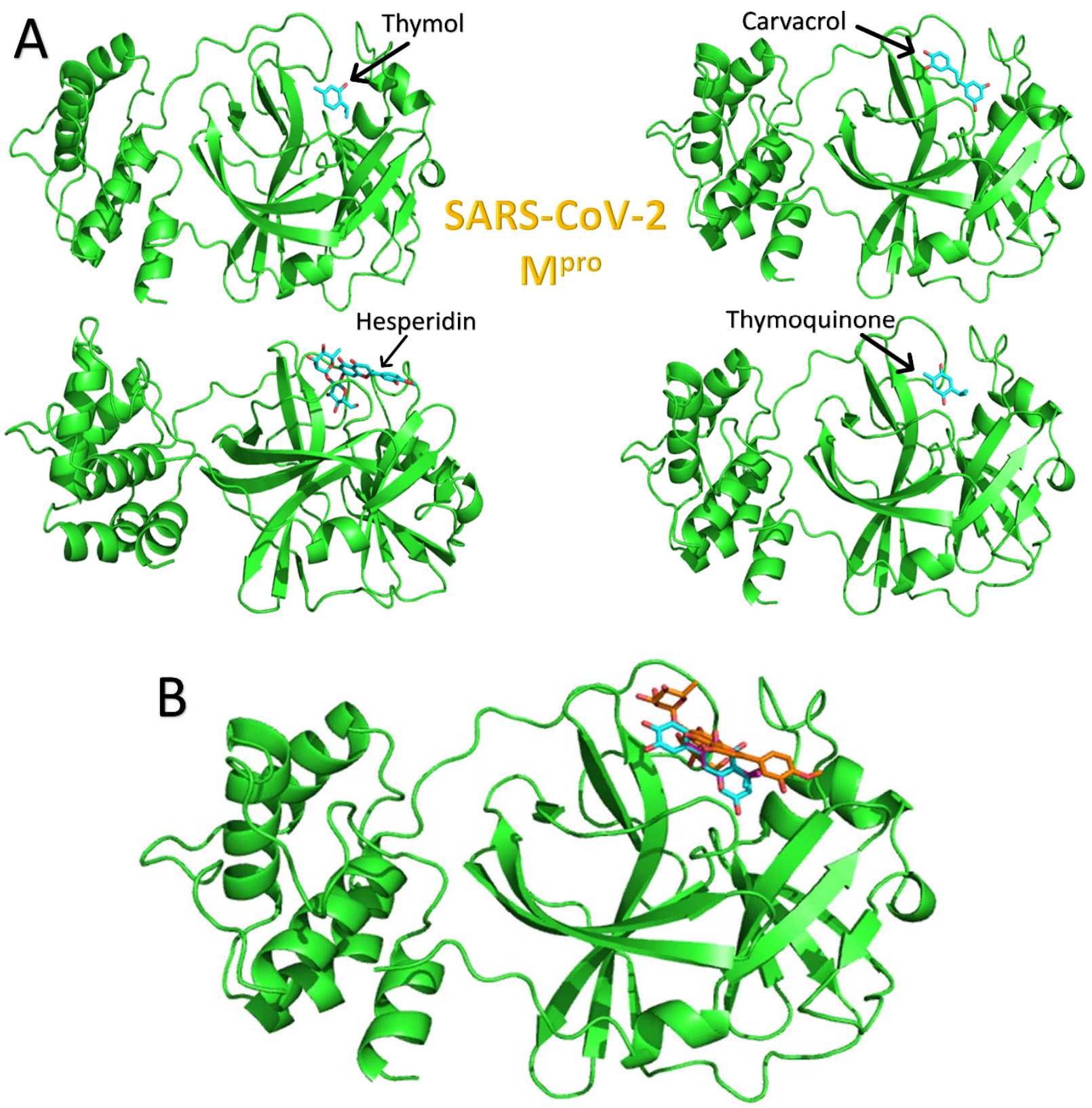

Figure 3 (A) The docking complexes formed after the docking of Thymol, Carvacrol, Hesperidine, and Thymoquinone into the SARS-CoV-2 $M^{\text {pro }}$ active site. (B) The superposition of all the compounds. The protein is represented with green cartoon, while ligands are in cyan and orange sticks. 
The half maximal inhibitory concentration (IC50) of Thymol, Carvacrol, Hesperidin, and Thymoquinone

The effect of different concentrations of the compounds on the cellular proliferation of Vero E6 cell line following $24 \mathrm{~h}$ of treatment was determined using MTT assay.

Results of the present work revealed a concentration-dependent cytotoxic effect of Thymol (617 $\mu \mathrm{M})$, Carvacrol $(464 \mu \mathrm{M})$, Hesperidine $(5.58 \mu \mathrm{M})$ and Thymoquinone $(3.9 \mu \mathrm{M})$ on Vero E6 cell line as shown in figure 4.

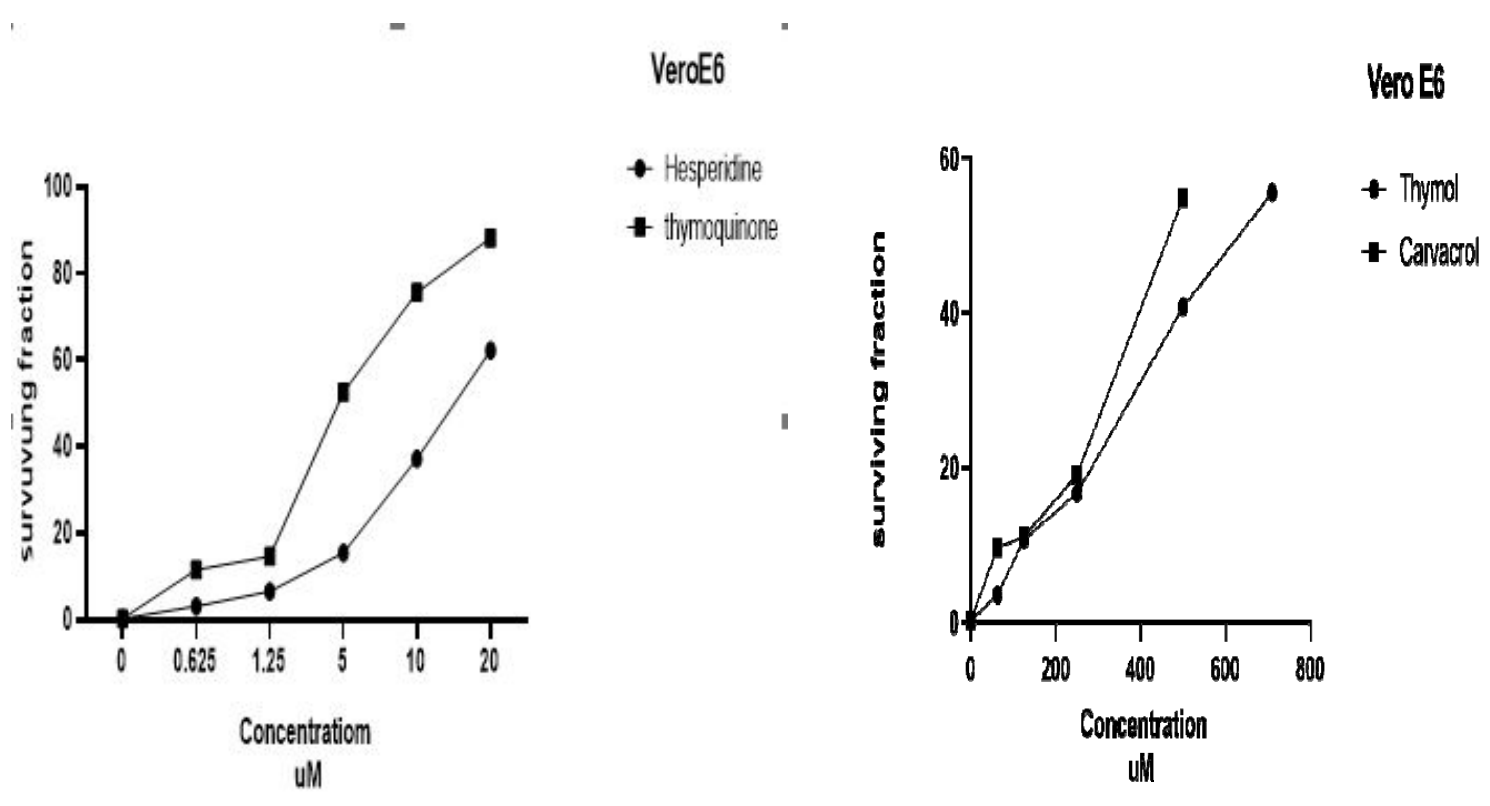

Figure 4: Effect of different concentrations Thymol, Carvacrol, Hesperidin and Thymoquinone on the cellular proliferation of Vero E6 cell line following $24 \mathrm{~h}$ of treatment. Values are expressed as the mean \pm SD $(n=3)$. Dose response curves were fitted using GraphPad prism 8.0.2 to determine IC50 values. 


\section{In vitro study for accessing the antiviral effect of natural products against SARS-CoV-2:}

Our results revealed that Hesperidine was the most affective natural product against SARS-CoV2 in Egyptians patients, as it caused inhibition to approximately $100 \%$ for infected Vero E6 cell line, Carvacrol, Thymoquinone caused inhibition to about 98\%, Chloroquine as a positive control caused inhibition to $98 \%$ and Thymol show the lowest inhibition percentage $96 \%$ for infected Vero E6 cell line.

The results showed significantly difference between natural products effect with (P-value < $0.0001)$ as shown in figure 5.

These results indicate that Hesperidine and other natural compounds as Carvacrol and Thymoquinone could be therapeutic agent against SARS-CoV-2 in Egypt as treatment resulted in the effective loss of essentially all viral material by time.

Eventually, development of an effective anti-viral for SARS-CoV-2, if given to patients early in infection, could help to limit the viral load, prevent severe disease progression and limit personperson transmission. Benchmarking testing of those natural compounds against other potential antivirals for SARS-CoV-2 with alternative mechanisms of action would thus be important as soon as practicable.

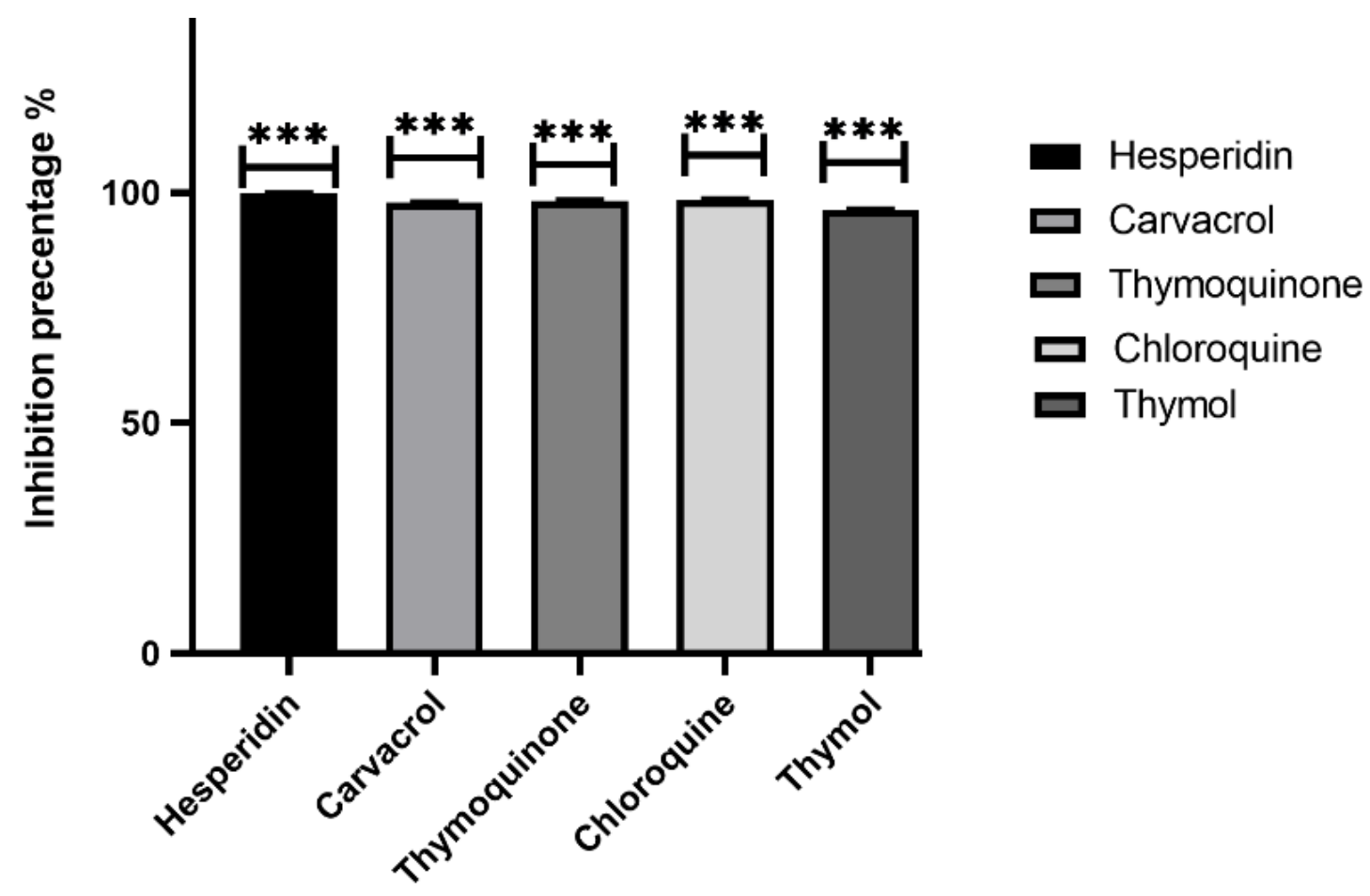

Figure 5: The antiviral effect of Hesperidin, Carvacrol, Thymoquinone, Chloroquine and Thymol against SARS-CoV-2 in vitro. The values are represented as means $\pm S D(n=2)\left({ }^{*} p<0.0001\right)$. 


\section{Competing Interest}

All the authors declare that there is no competing interest in this work.

\section{Data Availability}

The docking structures are available upon request from the corresponding author.

\section{References}

1. Chan JF-W, Yuan S, Kok K-H, et al. A familial cluster of pneumonia associated with the 2019 novel coronavirus indicating person-to-person transmission: a study of a family cluster. The Lancet 2020; 395(10223): 514-23.

2. Wu Z, McGoogan JM. Characteristics of and Important Lessons From the Coronavirus Disease 2019 (COVID-19) Outbreak in China: Summary of a Report of 72]314 Cases From the Chinese Center for Disease Control and Prevention. JAMA 2020; 323(13): 1239-42.

3. Wu J, Wu X, Zeng W, et al. Chest CT Findings in Patients With Coronavirus Disease 2019 and Its Relationship With Clinical Features. Investigative Radiology 2020; 55(5): 257-61.

4. Ultee A, Slump RA, Steging G, Smid EJ. Antimicrobial activity of carvacrol toward Bacillus cereus on rice. Journal of food protection 2000; 63(5): 620-4.

5. ULTEE A, SLUMP RA, STEGING G, SMID EJ. Antimicrobial Activity of Carvacrol toward Bacillus cereus on Rice. Journal of food protection 2000; 63(5): 620-4.

6. Zanwar AA, Badole SL, Shende PS, Hegde MV, Bodhankar SL. Cardiovascular effects of hesperidin: A flavanone glycoside. Polyphenols in human health and disease: Elsevier; 2014: 989-92.

7. Jadeja RN, Devkar RV. Polyphenols and flavonoids in controlling non-alcoholic steatohepatitis. Polyphenols in Human Health and Disease: Elsevier; 2014: 615-23.

8. Mollazadeh $\mathrm{H}$, Hosseinzadeh $\mathrm{H}$. The protective effect of Nigella sativa against liver injury: a review. Iranian journal of basic medical sciences 2014; 17(12): 958-66.

9. Rahmani AH, Aly SM. Nigella sativa and its active constituents thymoquinone shows pivotal role in the diseases prevention and treatment. Asian J Pharm Clin Res 2015; 8(1): 48-53.

10.Smith RD. Avicenna and the Canon of Medicine: a millennial tribute. Western Journal of Medicine 1980; 133(4): 367.

11. Ahmad A, Husain A, Mujeeb $M$, et al. A review on therapeutic potential of Nigella sativa: A miracle herb. Asian Pacific journal of tropical biomedicine 2013; 3(5): 337-52.

12. Ulasli M, Gurses SA, Bayraktar R, et al. The effects of Nigella sativa (Ns), Anthemis hyalina (Ah) and Citrus sinensis (CS) extracts on the replication of coronavirus and the expression of TRP genes family. Mol Biol Rep 2014; 41(3): 1703-11.

13.Salem AM, Bamosa AO, Qutub HO, et al. Effect of Nigella sativa supplementation on lung function and inflammatory mediatorsin partly controlled asthma: a randomized controlled trial. Annals of Saudi medicine 2017; 37(1): 64-71.

14. Boskabady $\mathrm{MH}$, Javan $\mathrm{H}$, Sajady M, Rakhshandeh $\mathrm{H}$. The possible prophylactic effect of Nigella sativa seed extract in asthmatic patients. Fundamental \& clinical pharmacology 2007; 21(5): 559-66.

15. Mahboubi M. Natural therapeutic approach of Nigella sativa (Black seed) fixed oil in management of Sinusitis. Integrative medicine research 2018; 7(1): 27-32. 
16.Elfiky AA, Ismail AM, Elshemey WM. Recognition of gluconeogenic enzymes; Icl1, Fbp1, and Mdh2 by Gid4 ligase: A molecular docking study. Journal of Molecular Recognition 2020; 33(5): e2831.

17.Leach A. Molecular Modelling: Principles and Applications (2nd Edition): Prentice Hall; 2001.

18. Elfiky AA. Novel guanosine derivatives against Zika virus polymerase in silico. Journal of Medical Virology 2020; 92(1): 11-6.

19.Ganesan A, Barakat K. Applications of Computer-Aided Approaches in The Development of Hepatitis C Antiviral Agents. Expert Opinion on Drug Discovery 2017; 12(4): 407-25.

20. Hasani HJ, Barakat KH. Protein-Protein Docking: Are We There Yet? Methods and Algorithms for Molecular Docking-Based Drug Design and Discovery: IGI Global; 2016: 173-95.

21. Elfiky AA, Ismail A. Molecular dynamics and docking reveal the potency of novel GTP derivatives against RNA dependent RNA polymerase of genotype 4a HCV. Life Sciences 2019; 238: 116958.

22.1.7.6 V. The PyMOL Molecular Graphics System, Version 1.7.6 Schrödinger, LLC.

23. Kim S, Thiessen PA, Bolton EE, et al. PubChem substance and compound databases. Nucleic acids research 2015; 44(D1): D1202-D13.

24.Berman H, Henrick K, Nakamura H. Announcing the worldwide Protein Data Bank. Nat Struct Biol 2003; 10(12): 980.

25. Morris GM, Huey R, Lindstrom W, et al. AutoDock4 and AutoDockTools4: Automated docking with selective receptor flexibility. J Comput Chem 2009; 30(16): 2785-91.

26. Trott O, Olson AJ. AutoDock Vina: improving the speed and accuracy of docking with a new scoring function, efficient optimization, and multithreading. J Comput Chem 2010; 31(2): 455-61.

27. Elfiky AA. Reply to a letter to the editor. Life sciences 2020; 252: 117715-.

28. Abu-Melha S, Edrees MM, Riyadh SM, Abdelaziz MR, Elfiky AA, Gomha SM. Clean Grinding Technique: A Facile Synthesis and In Silico Antiviral Activity of Hydrazones, Pyrazoles, and Pyrazines Bearing Thiazole Moiety against SARS-CoV-2 Main Protease (M(pro)). Molecules 2020; 25(19).

29.Elfiky AA, Ibrahim IM, Ismail AM, Elshemey WM. A possible role for GRP78 in cross vaccination against COVID-19. Journal of Infection.

30. Alaa Ismail AE. SARS-CoV-2 Spike behavior in situ: A Cryo-EM Images for a better understanding of the COVID-19 pandemic. Signal transduction and targeted therapy 2020; in press.

31.Elfiky A. SARS-CoV-2 Spike-Heat Shock Protein A5 (GRP78) recognition may be related to the immersed human coronaviruses. Frontiers in Pharmacology 2020; In press.

32. Yan R, Zhang Y, Li Y, Xia L, Guo Y, Zhou Q. Structural basis for the recognition of SARS-CoV-2 by fulllength human ACE2. Science 2020; 367(6485): 1444-8.

33. Hoffmann $M$, Kleine-Weber $H$, Schroeder S, et al. SARS-CoV-2 cell entry depends on ACE2 and TMPRSS2 and is blocked by a clinically proven protease inhibitor. Cell 2020.

34. Mendonca P, Soliman KF. Flavonoids Activation of the Transcription Factor Nrf2 as a Hypothesis Approach for the Prevention and Modulation of SARS-CoV-2 Infection Severity. Antioxidants 2020; 9(8): 659.

35. Mariappan V, S. R. R, Balakrishna Pillai A. Angiotensin-converting enzyme 2: A protective factor in regulating disease virulence of SARS-COV-2. IUBMB Life; $\mathrm{n} / \mathrm{a}(\mathrm{n} / \mathrm{a})$.

36. Mosmann T. Rapid colorimetric assay for cellular growth and survival: Application to proliferation and cytotoxicity assays. Journal of Immunological Methods 1983; 65(1): 55-63.

37. Hayden FG, Cote KM, Douglas RG, Jr. Plaque inhibition assay for drug susceptibility testing of influenza viruses. Antimicrobial agents and chemotherapy 1980; 17(5): 865-70.

38. Adem Ş, Eyupoglu V, Sarfraz I, et al. Caffeic acid derivatives (CAFDs) as inhibitors of SARS-CoV-2: CAFDs-based functional foods as a potential alternative approach to combat COVID-19. Phytomedicine 2020: 153310.

39. Elfiky AA. Natural products may interfere with SARS-CoV-2 attachment to the host cell. Journal of Biomolecular Structure and Dynamics 2020: 1-10. 
40.Noor NA, Fahmy HM, Mohammed FF, Elsayed AA, Radwan NM. Nigella sativa amliorates inflammation and demyelination in the experimental autoimmune encephalomyelitis-induced Wistar rats. Int J Clin Exp Pathol 2015; 8(6): 6269-86.

41.Elfiky AA, Baghdady AM, Ali SA, Ahmed MI. GRP78 targeting: Hitting two birds with a stone. Life Sciences 2020; 260: 118317.

42.Elfiky AA. Anti-HCV, nucleotide inhibitors, repurposing against COVID-19. Life Sciences 2020; 248: 117477.

43.Elfiky AA. Ribavirin, Remdesivir, Sofosbuvir, Galidesivir, and Tenofovir against SARS-CoV-2 RNA dependent RNA polymerase (RdRp): A molecular docking study. Life Sciences 2020; 253: 117592.

44. Elfiky AA. SARS-CoV-2 RNA dependent RNA polymerase (RdRp) targeting: an in silico perspective. Journal of Biomolecular Structure and Dynamics 2020: 1-9.

45.Jin Z, Du X, Xu Y, et al. Structure of Mpro from SARS-CoV-2 and discovery of its inhibitors. Nature 2020; 582(7811): 289-93.

46.Ibrahim IM, Abdelmalek DH, Elshahat ME, Elfiky AA. COVID-19 spike-host cell receptor GRP78 binding site prediction. Journal of Infection 2020; 80(5): 554-62.

47. Korber B, Fischer WM, Gnanakaran S, et al. Tracking Changes in SARS-CoV-2 Spike: Evidence that D614G Increases Infectivity of the COVID-19 Virus. Cell 2020; 182(4): 812-27.e19.

48. Ke Z, Oton J, Qu K, et al. Structures and distributions of SARS-CoV-2 spike proteins on intact virions. Nature 2020. 